\title{
Correction to: Genetic characterization of Addison's disease in Bearded Collies
}

Liza C. Gershony ${ }^{1,2}$, Janelle M. Belanger ${ }^{1}$, Marjo K. Hytönen ${ }^{3}$, Hannes Lohi ${ }^{3}$, Thomas R. Famula ${ }^{1}$ and Anita M. Oberbauer ${ }^{1 *}$

\section{Correction to: BMC Genomics (2020) 21:833 \\ https://doi.org/10.1186/s12864-020-07243-0}

Following publication of the original article [1], it was noted that due to a typesetting error the caption of Fig. 1 was mistakenly captured within the main body of the article.

Furthermore, the layout of the online versions of Tables 1 and 2 have been updated to improve the presentation of the genotype comparisons.

The correct Fig. 1 with the caption has been included in this Correction article, and the original article has been updated.

\section{Author details}

'Department of Animal Science, University of California-Davis, Davis, CA 95616, USA. ${ }^{2}$ Brazilian National Council for Scientific and Technological Development (CNPq) fellow, Brasilia, DF 71605, Brazil. ${ }^{3}$ Department of Medical and Clinical Genetics, and Department of Veterinary Biosciences, University of Helsinki, 00014 Helsinki, Finland; Folkhälsan Research Center, Helsinki 00290, Finland.

Published online: 30 December 2020

\section{Reference}

1. Gershony LC, Belanger JM, Hytönen MK, et al. Genetic characterization of Addison's disease in Bearded Collies. BMC Genomics. 2020;21:833. https:// doi.org/10.1186/s12864-020-07243-0.

The original article can be found online at https://doi.org/10.1186/s12864020-07243-0

* Correspondence: amoberbauer@ucdavis.edu

'Department of Animal Science, University of California-Davis, Davis, CA 95616, USA

Full list of author information is available at the end of the article

(c) The Author(s). 2020 Open Access This article is licensed under a Creative Commons Attribution 4.0 International License, which permits use, sharing, adaptation, distribution and reproduction in any medium or format, as long as you give appropriate credit to the original author(s) and the source, provide a link to the Creative Commons licence, and indicate if changes were made. The images or other third party material in this article are included in the article's Creative Commons licence, unless indicated otherwise in a credit line to the material. If material is not included in the article's Creative Commons licence and your intended use is not permitted by statutory regulation or exceeds the permitted use, you will need to obtain permission directly from the copyright holder. To view a copy of this licence, visit http://creativecommons.org/licenses/by/4.0/ The Creative Commons Public Domain Dedication waiver (http://creativecommons.org/publicdomain/zero/1.0/) applies to the data made available in this article, unless otherwise stated in a credit line to the data. 


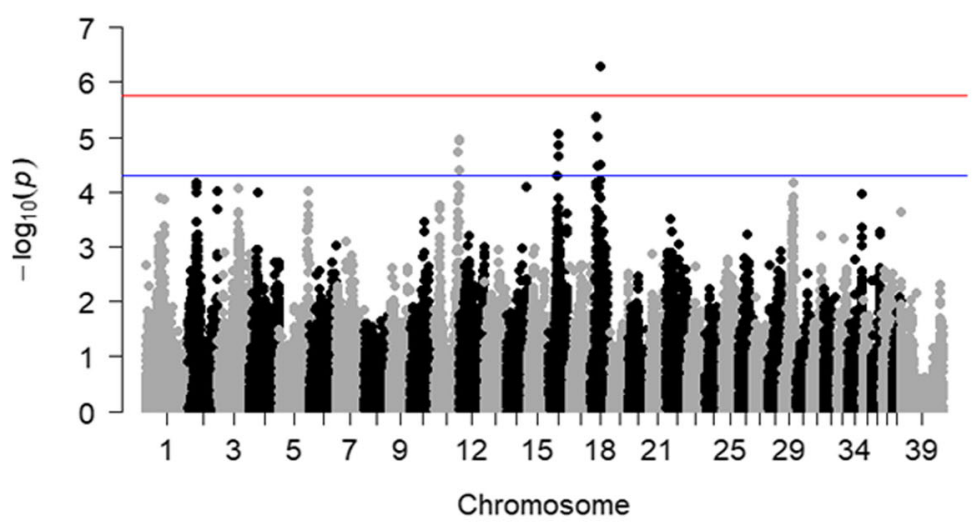

(a)

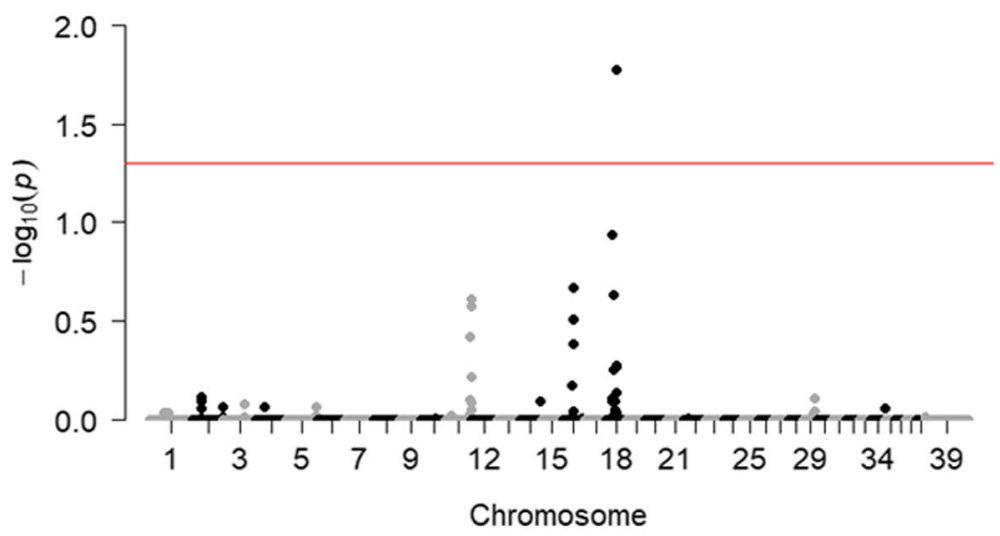

(b)

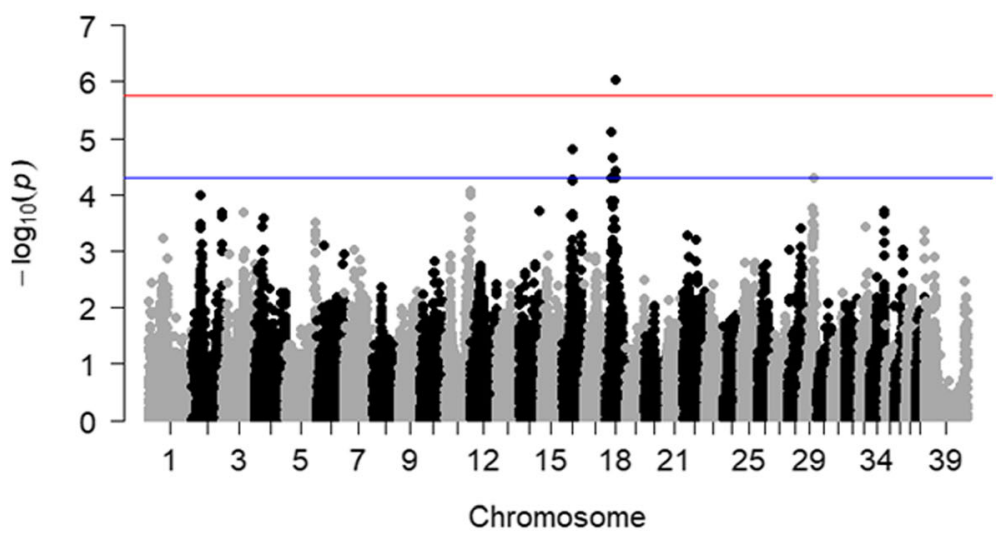

(c)

Fig. 1 Manhattan Plots. Chi-square based allelic association (a) and association testing after 100,000 max(T) permutations (b) in PLINK for 103 unrelated Bearded Collies ( 41 cases, 62 healthy controls; $\lambda G C=1.2280$ ). c Association testing using GEMMA's univariate linear mixed model approach to account for population substructure of the same dataset $\lambda G C=1.0328)$. The blue and red lines indicate suggestive $(p<0.00005$; $-\log 10[p$-value] $\geq 4.3)$ and Bonferroni-adjusted genome-wide significance threshold (-log10[p-value] $\geq 5.75$ ), respectively 